\title{
A rare cause of ischemic chest pain: Congenital Ostial Atresia of the right coronary artery
}

\author{
Talat Tavlı ${ }^{1}$, Alkım Alkan ${ }^{1}$, Özgür Bayturan ${ }^{1}$, Ozan Ütük ${ }^{1}$, Onur Dalgıç ${ }^{1}$, \\ Nihat Madak ${ }^{1}$, Bora Kamalı
}

1) Celal Bayar University, Medical Faculty, Department Of Cardiology, Manisa, Turkey

2) Department Of Radiology, Universal Hospital, Manisa, Turkey

\begin{abstract}
Summary
The prevalence of congenital coronary anomalies is reported in about $0.5 \%$ to $1.5 \%$ of patients undergoing coronary angiography. Tüccar E. And Elhan A. Just reported coronary artery anomalies in adult Turkish population. They analysed 5000 coronary angiograms. Twenty-five $(0.5 \%)$ coronary arteries with anomalous origins were found. We are presenting an extremely rare right coronary origin abnormality. In this case right coronary artery originates from left anterior descending coronary artery. According to general opinion, coronary segments with an anomalous course are no more susceptible to coronary atherosclerosis than normal segments in the same individual. Only $10.1 \%$ of patients with congenital coronary artery anomalies (CCAA) identified during cardiac catherization, had another congenital heart defect. Coronary artery anomalies are very important because coronary artery anomalies rank second as a cardiovascular cause of sudden death in the young, behind hypertrophic cardiomyopathy.
\end{abstract}

Keywords: Congenital coronary anomalies, ostial atresia, coronary atherosclerosis.

\section{Introduction}

The prevalence of congenital coronary anomalies is reported in about $0.5 \%$ to $1.5 \%$ of patients undergoing coronary angiography. ${ }^{(1)}$ Tüccar E. And Elhan A. Just reported coronary artery anomalies in adult Turkish population. They analysed 5000 coronary angiograms. Twenty-five $(0.5 \%)$ coronary arteries with anomalous origins were found. ${ }^{(2)}$ We are presenting an extremely rare right coronary origin abnormality. In this case right coronary artery originates from left anterior descending coronary artery. According to general opinion, coronary segments with an anomalous course are no more susceptible to coronary atherosclerosis than normal segments in the same individual. Only $10.1 \%$ of patients with congenital coronary artery anomalies (CCAA) id- 
entified during cardiac catherization, had another congenital heart defect. ${ }^{(3)}$ Coronary artery anomalies are very important because coronary artery anomalies rank second as a cardiovascular cause of sudden death in the young, behind hypertrophic cardiomyopathy. ${ }^{(4)}$

\section{Case:}

Initial Presentation: 55 year-old male with chest pain without any radiation, diaphoresis, and nausea.

History of Present Complain: Two months ago, after his first physical examination, he was treated by an emergency room physician at a local hospital. His history was very likely to myocardial infarction.

Transthoracic echocardiography showed: LV global hypokinesia LV EF: \%50, LV diastolic dysfunction, LV consantric hypertrophy, mitral regurgitation (1-2 plus), trivial aortic regurgitation, aortic root: $47 \mathrm{~mm}$,

ECG: SR, HR: 61 beat per min, V1-4 R amplitude missing, LAHB

Past medical history: DM (+), HT (+), DL (+), AÖ $(+)$, MI (?)

Coronary Angiography: The right coronary artery originating from the proximal segment (after diagonal-1) of left anterior descending artery. There were no obstructive lesions.

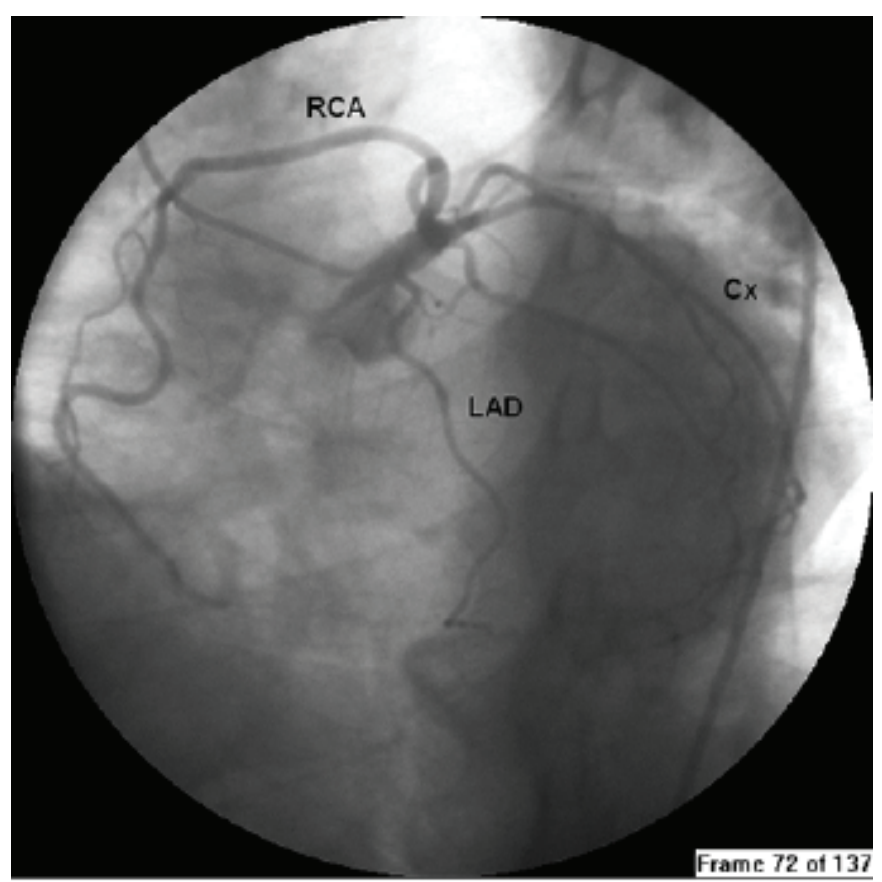

On physical examination, patient has a BP of 130/70 and a heart rate of $61 \mathrm{bpm}$ regular. He has no jugular venous hypertension. The point of maximal impulse is not palpable. He has a grade 3/6 systolic ejection murmur in the mitral area. He had no diastolic murmur and his lungs were clear, good peripheral pulses, and no bruits.

\section{Discussion}

In large retrospective series coronary anomalies were categorized as either anomalies of origin and distribution. The prevalence of coronary anomalies in Hobbs and Yamanaka series were reported as $1.55 \%$ and $1.3 \%{ }^{(5)}$ There have been at least 37 published reports of an anomalies artery arising from the LAD, coursing anterior to right ventricular outflow tract to supply the usual RCA territory. The segment of origin from the LAD is either proximal or mid LAD. When you review the literature the frequency of this originating segment changes according to the used nomenclature.

In our case the anomalous RCA was originating from the mid LAD just after the 1.st diagonal branch.

There is no clear agreement of the clinical significance of an anomalous RCA from the LAD. While some authors suggest such an anomaly is usually benign and there appears to be no increased incidence of coronary atherosclerosis in such patients. On the other hand some authors suggest the opposite to be true. The

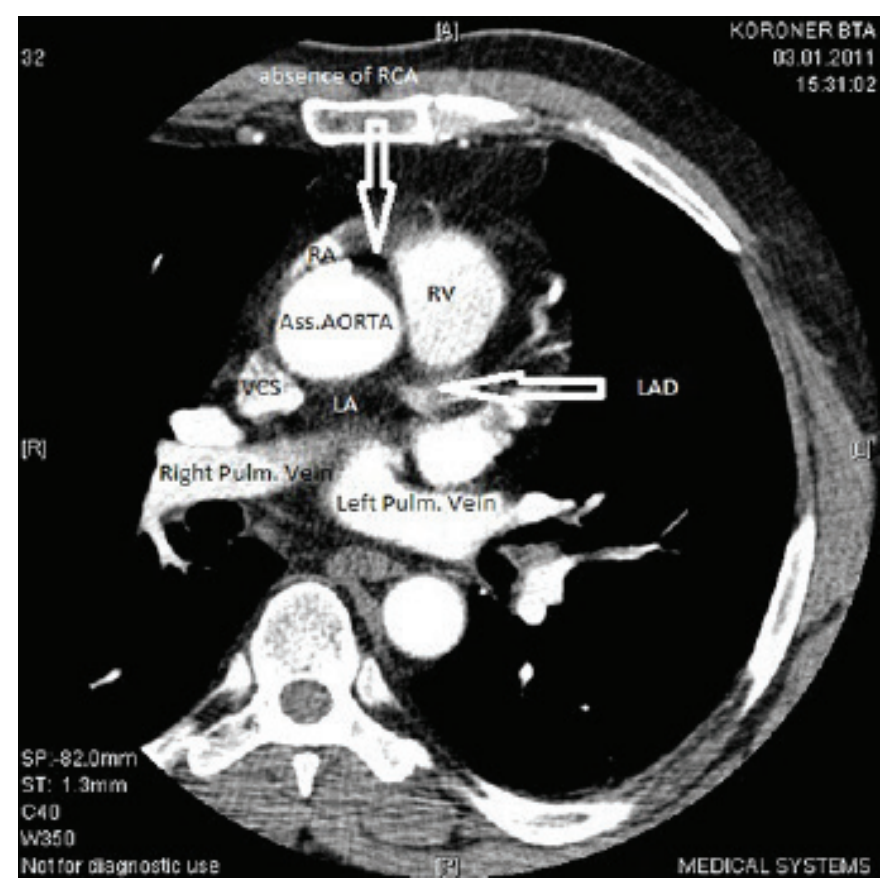


presence of an additional major artery near the first diagonal may increased to the tendecy of narrowing at this point. Another possibility is the presence of ischemia without overt coronary atherosclerosis due to reduced flow velocities in the anomalous vessel. In case of a sharp angle of take-off for the anomalous vessel, flow velocities may be reduced.

In our case there was no obstructive coronary artery lesion despite a an acute angle greater than 90 degrees.

In conclusion, majority of anomalous right coronary arteries have their origin from the mid LAD segment as defined by CASS (Coronary Artery Surgery Study) nomenclature. ${ }^{(6)}$ There is some disagreement regarding the association of this anomaly and increased coronary atherosclerosis.

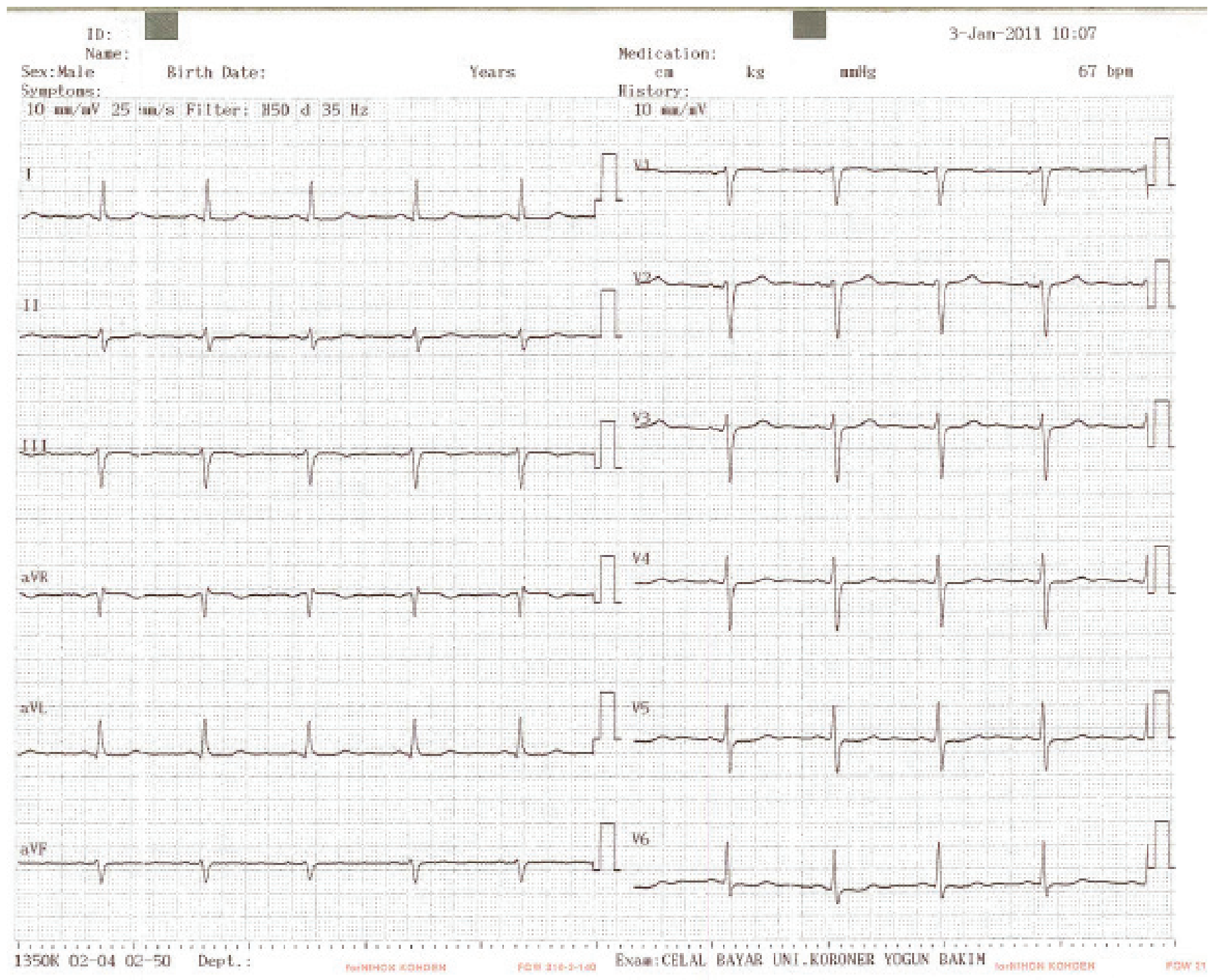




\section{References}

1. Poulis M. Anomalous Origin of the Right Coronary Artery. Clin. Cardiol. 1999; 22: 815

2. Tüccar E, Elhan A. Examination of Coronary Artery Anomalies in an Adult Turkish Population. Turk J Med Sci. 2002; 32: 309-312.

3. Tuzcu EM, Moodie DS, Chambers IL, Kayser P, Hobbs RE. Congenital heart diseases associated with coronary artery anomalies. Cleve Clin J Med 1990; 57: 147-152.

4. Taylor AJ, Virmani R. Coronary Artery Anomalies In: Crawford. M. H.
Di Marco J.P, ed. Cardiology Mosby 2001; 2: 10-11.

5. Yamanaka O, Hobbs RE. Coronary artery anomalies in 126.595 patients undergoing coronary angiography. Cathet Cardiovasc Diagn 1990; 21: 28-40

6. Click RL, Holmes DR Jr, Vliestra RE, Kosinski AS, Kronmal RA. Anomalous coronary arteries;location, degree of atherosclerosis and effect on survival a report from the Coronary Artery Surgery Study. $J$ Am Coll Cardiol 1989; 1;13: 531-7.

Received: 06/11/2013

Accepted: 24/03/2014

Published: 20/05/2014

\section{Disclosure and conflicts of interest:}

Conflicts of interest were not reported.

\section{Corresponding author:}

Dr. Talat Tavlı

ttavli@yahoo.com 